\title{
LA REAL CABALLERIZA EN TIEMPOS DE CARLOS III: REFORMAS Y COMPOSICIÓN (1759-1788) ${ }^{1}$
}

\author{
David Quiles Albero \\ (Instituto Universitario La Corte en Europa-Universidad Autónoma de Madrid)
}

\section{RESUMEN}

El siglo XVIII fue un periodo de grandes cambios dentro de la Casa Real. Dentro de ella, la Real Caballeriza siguió jugando un papel determinante como gran gestora de las salidas públicas del monarca.

En tiempos de Carlos III, la reforma aprobada el 11 de septiembre de 1761 alteró notablemente los cimientos de la institución. Tras la unificación de las Caballerizas del rey y de la reina, fue necesaria una redistribución de muchos dependientes, que en muchos casos se quedaron sin plaza hasta surgir una vacante de su oficio. Así mismo, hubo significativos cambios en la planta que también requieren ser analizados.

Finalmente, cabe reseñar que, como en cualquier ordenanza de este tipo, la parte económica sería fundamental. Por ello, no erramos al afirmar que el gran objetivo por el que se aprobó esta nueva planta fue reducir el gasto que la Caballeriza suponía para el erario regio.

PALABRAS CLAVE: Real Caballeriza, Caballeriza del rey, Casa Real, Carlos III, Ceremonial, Caballerizo mayor.

\section{THE ROYAL MEWS IN TIMES OF CHARLES III: REFORMS AND COMPOSITION (1759-1788)}

\begin{abstract}
Eighteenth century was a time of change in the Spanish Royal House. Within it, the Royal Mews kept on playing a very important role as managers of the public exits of the King.

\footnotetext{
1 Este trabajo ha sido posible gracias a un contrato FPI del Ministerio de Economía y Competitividad dentro del proyecto con número de referencia HAR2015-68946-C3. Así mismo, se adscribe al proyecto concedido dentro de la Convocatoria de Programas de I+D en Ciencias Sociales y Humanidades 2015 de la Comunidad de Madrid La herencia de los sitios reales. Madrid, de corte a capital (Historia, Patrimonio y Turismo) (H2015/HUM 3415) financiado por el Fondo Social Europeo.
} 
During the reign of Carlos III, the reform approved on September 11, 1761, altered the basis of the institution. After the unification of the King and Queens Mews, it was necessary to redistribute many dependents, who in many cases were left without a seat until the emegence of a vacancy. Likewise, there were significant changens in the composition of each department that also need to be analyzed.

To sum up, it must be noted that, as in any ordinace of this type, the economic part would be essential. Therefore, we do not err in stating that this new arrangement was approved to reduce the expense that the Mews represented for the royal treasury.

KEY WORDS: Royal Mews, Kings mews, Royal House, Carlos III, Ceremonial, Master of the King's Horse.

\section{LA AUTONOMÍA DE LAS REALES CABALLERIZAS}

De entre las diferentes ramas que componían la Casa Real en el siglo XVIII, la Caballeriza era sin lugar a dudas la que gozaba de mayor autonomía. A la hora de entender esta independencia, debemos aludir esencialmente a su composición y a sus funciones.

La Caballeriza era el cuerpo más numeroso de la Casa Real. El número total de sus integrantes - que llegó a rondar los mil individuos- no dejó de aumentar en tiempos de Carlos III. Tras la reforma de 1761, a la que aludiremos posteriormente, eran aproximadamente 786 los individuos que la componían. Diez años más tarde, eran ya 879 , mientras que en 1782 el total de servidores ascendía a $952^{2}$. A esta cantidad habría que sumar los individuos de fuera de planta, un cuerpo de la institución que también fue creciendo a lo largo del reinado.

Por otro lado, su disociación se entiende si tenemos en cuenta la particularidad de sus desempeños cotidianos. La Real Caballeriza era uno de los ámbitos más técnicos dentro de la Casa Real, cuyos individuos llevaban a cabo labores altamente especializadas - tanto en lo administrativo como en el cuidado de los animales y enseres - por lo que se requería un número muy amplio de oficios de manos $^{3}$.

\footnotetext{
2 Archivo General de Palacio [AGP], Reinados, Carlos III, Caballerizas, caja 560, s.f., nómina de planta del mes de enero de 1762; caja 572, s.f., nómina de planta del mes de enero de 1772; caja 582, s.f., nómina de planta del mes de enero de 1782 .

${ }^{3}$ Rubén Mayoral López y Alejandro López Álvarez, "La caballeriza", en La monarquía de Felipe III, coord. José Martínez Millán, vol. 1, (Madrid: Fundación Mapfre, 2008), 733.
} 
Además, como bien ha señalado Marcelo Luzzi, «a lo largo del siglo XVII, la caballeriza mantuvo una dualidad explicativa de su razón de ser: por un lado presentar ceremonial (y metafóricamente) la soberanía, en tanto que doma y cuidado del caballo» ${ }^{4}$.

Por tanto, la Real Caballeriza no era solo un lugar en el que se cuidaban caballos y mulas. Su labor primordial era gestionar los momentos en los que el monarca se mostraba ante sus súbditos: ceremonias, paseos y jornadas. Acontecimientos en los que se ponía de manifiesto todo el poderío regio y que, en definitiva, daban a la institución la capacidad de ser la gestora de la movilidad del rey, con toda la vistosidad y espectacularidad requeridas ${ }^{5}$.

Ante una vida de puertas para dentro del Palacio Real, estas ceremonias, celebradas en ocasiones muy concretas, constituían el punto de acceso del pueblo a su rey y al resto de la Corte ${ }^{6}$. Por tanto, la importancia de la Caballeriza resulta indiscutible al desempeñar este rol fundamental en la gestión de las apariciones públicas de la familia real.

\section{LA REFORMA DE 1761: LA UNIFICACIÓN DE LAS REALES CABALLERIZAS}

En enero de 1760, a los pocos meses de su regreso a Madrid, Carlos III remitía un Real Decreto en el que manifestaba su deseo de: «hallarse instruido de las clases e individuos de que se componen su real caballeriza, ballestería y casa de sus caballeros pajes». Por ello, pedía al veedor general

le pase a sus reales manos una relación individual del número de individuos de cada clase con expresión de los que lo sean del de la planta, de los supernumerarios de ella y de los supernumerarios de fuera de planta, especificándose también su antigüedad, los sueldos asignados y que cada uno goza por su respectivo empleo y los sobresueldos, pensiones o daciones que al mismo tiempo desfrutan ${ }^{7}$.

El monarca, que llegó acompañado por un gran número de servidores napolitanos, rápidamente debió ser consciente de la necesidad de llevar a cabo una reforma, más práctica que teórica, que regulase la composición de las Casas Reales.

\footnotetext{
${ }^{4}$ Marcelo Luzzi Traficante, "Domesticidad, oficios y fidelidad: la Caballeriza Real y la unificación de las Casas Reales en la primera mitad del siglo XVIII", en Libros de la Corte, 14 (2017), 157.

${ }^{5}$ Miguel Ángel Gacho Santamaría, "Las Reales Caballerizas en el Antiguo Régimen" (Tesis doctoral: Madrid, 2001), 5.

${ }^{6}$ Eduardo Galán Domingo, "De las Reales Caballerizas a la Colección de Carruajes del Patrimonio Nacional”, en Arbor, XLXIX (2011), 222.

${ }^{7}$ AGP, Reinados, Carlos III, Caballerizas, caja 22, exp. 01, s.f., carta del rey al veedor general de la Caballeriza del rey del 18 de enero de 1760.
} 
A ello cabe sumar la prematura muerte de la reina María Amalia el 27 de septiembre de 1760. Tras el fallecimiento de su esposa, el rey decidió no volver a contraer matrimonio, por lo que la Casa de la reina dejaba de tener utilidad.

Estos dos elementos son esenciales para entender la necesidad de una nueva reforma, siendo tan reciente la llevada a cabo por Fernando VI en 1749. Ese mismo año se llevó a cabo el famoso catastro de Ensenada, que buscaba reglar los ingresos ${ }^{8}$. Por su parte, la regulación del gasto vino con una ordenanza que unifico, y a la vez eliminó, las Casas de Castilla y Borgoña. Del mismo modo, a partir de ese momento solo seguirían existiendo las Casas del rey y de la reina, suprimiéndose el resto?.

El nuevo monarca debió juzgar estas modificaciones como insuficientes. En consecuencia, el 27 de octubre de 1760 ordenaría la incorporación de la Caballeriza de su difunta esposa a la suya propia ${ }^{10}$. Esta unificación sería uno de los pilares fundamentales de la renovada Casa Real, siguiendo en muchos aspectos la reforma llevada a cabo en Nápoles en el año $1738^{11}$.

Paralelamente, es necesario enfatizar el hecho de que la reforma para la Casa Real apenas menciona a la Caballeriza y sus dependencias. Su particularidad era tal que se precisaba de un reglamento específico, fuera de aquel en el que se definirían las particularidades de las restantes ramas destinadas al servicio regio. Al inicio del mismo, se pondría de manifiesto lo que verdaderamente se perseguía con la unión de las Caballerizas, que no era sino evitar «por este medio superfluidades que contribuyen más que al decoro a la confusión», dando cuenta de una visión claramente funcional ${ }^{12}$.

En esta misma línea, el otro gran desafío que se perseguía era regular la servidumbre, estableciendo un número fijo de individuos para cada oficio. El marqués de Campo Villar lo dejaba claro al duque de Medinaceli, caballerizo mayor, en una carta del 11 de septiembre de 1761 con las siguientes palabras:

Habiendo resuelto el rey establecer la servidumbre de sus reales caballerizas, ballestería y casa de caballeros pajes a un número determinado de criados,

\footnotetext{
${ }^{8}$ Carlos Gómez Centurión, "La reforma de las Casas Reales del marqués de la Ensenada", en Cuadernos de Historia Moderna 20 (1998), 59-83.

${ }^{9}$ AGP, Administración General, leg. 939, exp. 57, Reglamento de la Real Casa de 1749.

10 AGP, Reinados, Carlos III, Caballerizas, caja 22, exp.01, s.f., Real Orden comunicada al veedor general Juan Francisco de Garaicoechea del 4 de noviembre de 1760.

11 Acerca de la corte napolitana de Carlos III, véase Pablo Vázquez Gestal, "Corte, poder y cultura política en el Reino de las Dos Sicilias de Carlos de Borbón (1734-1759)" (Tesis doctoral: Madrid, 2008)

12 AGP, Reinados, Carlos III, Caballeriza, caja 599, exp. 03, composición de la Real Caballeriza tras la reforma de 1761 .
} 
con la reunión de las que servían a la difunta reina nuestra señora, para que dese ahora en adelante no haya más que una sola ${ }^{13}$.

Esta misiva, que resume a la perfección las intenciones de Carlos III, fue escrita el mismo día en que fueron publicados los tres nuevos reglamentos que fijarían la composición de la que a partir de entonces sería la única Caballeriza regia: uno en el que señalaban los cargos, sueldos y servicios en el cual centraremos los siguientes apartados del presente artículo [Anexo 1], otro en el que se estipulaba la instrucción que debían seguir las oficinas de cuenta y razón y un tercero destinado a los individuos de fuera de planta y jubilados.

En todos ellos, salta a la vista que lo que verdaderamente se perseguía era la regulación del gasto destinado a la Real Caballeriza. Al fin y al cabo, en este tipo de ordenanzas la parte financiera era primordial, debiendo figurar junto a cada cargo sus gajes y pensiones ${ }^{14}$. Este nuevo reglamento no sería la excepción y, además, en el capítulo 24 del mismo se dejaba claro que la junta de bureo - a través de reuniones anuales - debía ser la encargada de:

examinar los gastos que se hubieren causado en el año antecedente, atendiendo a los que puedan evitarse sin faltar a la decencia correspondiente. Y así mismo se examinarán las cuentas y verá si se llevan corrientes y sin atraso con las debidas formalidades prescritas en el reglamento ${ }^{15}$.

Esta junta estaría formada por el mayordomo mayor, el caballerizo mayor, sumiller, patriarca, contralor y grefier de la Casa Real, así como el contador y el veedor general de la Real Caballeriza. No obstante, desde 1749 sus competencias habían disminuido sustancialmente. Con la reforma de ese año, el bureo quedó apartado de las funciones económicas, que pasaron a la Secretaría de Hacienda. En consecuencia, se le asignaría un presupuesto cerrado de antemano al que debía adaptarse, frente a la política de gasto ilimitado que hasta entonces se había seguido. Sus atribuciones quedarían reducidas al ámbito judicial, siendo en la práctica un nuevo tribunal dentro del palacio desposeído de sus facultades tradicionales ${ }^{16}$.

Esta estrategia seguida por el marqués de la Ensenada pretendía arrebatar este poder contable a los jefes del palacio. Estos habían sido hasta entonces los

13 AGP, Reinados, Carlos III, Casa, leg. 138, s.f., carta del marqués de Campo Vilar para el duque de Medinaceli del 11 de septiembre de 1761.

${ }^{14}$ José Eloy Hortal Muñoz y Félix Labrador Arroyo, La Casa de Borgoña. La Casa del rey de España (Leuven: Leuven University Press, 2014), 37.

${ }^{15}$ AGP, Reinados, Carlos III, Caballerizas, leg. 312, s.f., capítulo 24 del reglamento del 11 de septiembre de 1761.

${ }^{16}$ Emilio de Benito, "La real Junta de Bureo", en Cuadernos de Historia del Derecho, 1 (1994), 61. Así mismo, al respecto de la Junta se pueden consultar también: José Martínez Millán y Javier Ezquerra Revilla, "La Real Junta de Bureo", en La Corte de Felipe IV (1621-1665). Reconfiguración de la Monarquía católica, dirs. José Martínez Millán y José Eloy Hortal Muñoz, Tomo I, vol. 1 (Madrid: Polifemo, 2015), 167-316. 
encargados de ejecutar los pagos, pero también de supervisar la contabilidad. Por ello, en la práctica, este sistema hacía que el control externo fuese imposible.

Carlos III reafirmó la función inspectora del superintendente general, quien, como apuntó en su día Gómez Centurión, «era el instrumento a través del cual se acabaría estableciendo un férreo control ministerial sobre toda la estructura de las Casas Reales ${ }^{17}$. Por ello, en la práctica, la poca vitalidad y utilidad de la junta de bureo quedó de manifiesto, ya que durante el reinado de Carlos III únicamente se convocó en tres ocasiones: comienzos de 1780, diciembre de 1785 y diciembre de 1787; fechas en las que se estudiaron las cuentas de los gastos ocasionados en la Real Caballeriza desde la celebración de la última reunión [Anexo 2] ${ }^{18}$.

No obstante, el proyecto de unificación de ambas Caballerizas no tuvo en cuenta un aspecto fundamental: el procedimiento por el cual se debía regular la integración de los individuos que procedían de las extintas Caballerizas de la reina y reina madre. Por ello, el 10 de septiembre de 1766 se emitiría una real orden apuntando que

después de remplazados los criados de su real caballeriza exclusos de planta de las reales servidumbres [los que procedían de la caballeriza de la reina María Amalia], tuviese yo [el Caballerizo Mayor] presente a los individuos de la caballeriza de la reina madre nuestra señora que este en gloria para incluirlos en las vacantes de número ${ }^{19}$.

\section{LA COMPOSICIÓN DE LA REAL CABALLERIZA DURANTE EL REINADO DE CARLOS III (1759-1788)}

Desde tiempos de los Austrias, el gran contingente de servidores de las Casas Reales hizo que el pago de sus gajes, raciones, ayudas de costa, vestuarios, pensiones y mercedes fuese siempre el gasto principal de la Corte $^{20}$.

En el siglo XVIII, con una plantilla que no hizo más que crecer, la Real Caballeriza se mantuvo dividida por motivos funcionales en diferentes departamentos, todos ellos bajo la jurisdicción del caballerizo mayor. En primer lugar,

\footnotetext{
${ }^{17}$ Gómez Centurión, "La reforma de las casas reales", 72.

18 AGP, Reinados, Carlos III, legajo 312, Representación de la Junta de Bureo sobre asuntos de la Real Caballeriza entre 1763-1787.

${ }^{19}$ Esta real orden es mencionada por el duque de Medinaceli en el nombramiento de Juan González como ayudante del cuartel de coches el 25 de marzo de 1767, quien había ocupado dicha plaza en la extinta caballeriza de la reina. AGP, Reinados, Carlos III, caja 25, exp.01, s.f., carta del caballerizo mayor al veedor general del 25 de marzo de 1767.

${ }^{20}$ Carlos Gómez-Centurión Jiménez y Juan A. Sánchez Belén (eds.), La herencia de Borgoña. La bacienda de las Reales Casas durante el reinado de Felipe $V$ (Madrid: Centro de Estudios Políticos y Constitucionales, 1998), 16-17.
} 
cabe citar los empleos vinculados con los cortejos o actos ceremoniales: reyes de armas, maceros, timbaleros y trompetas, armeros, ballesteros, caballeros pajes, etc. Encontramos además varios cuarteles: el de regalada (encargado de los caballos de monta), el de animales de tiro y el del guadarnés general ${ }^{21}$. Mención especial requieren también la Real Ballestería y las Yeguadas de Aranjuez, que en esta época dependían o pasaron a depender también del caballerizo mayor.

En ellos centraremos nuestro análisis, dejando a un margen a los individuos de fuera de planta. Simplemente señalar que en esta sección se incluía fundamentalmente a los individuos que habían formado parte de las extintas Caballerizas y que, tras su desaparición, habían quedado sin una plaza de número. No obstante, en ella se incluyen también jubilados, viudas y huérfanos de antiguos servidores, los cuales copaban también una parte importante del gasto.

\subsection{Altos cargos}

\subsubsection{Caballerizo y ballestero mayor}

El de caballerizo mayor era sin lugar a dudas uno de los cargos más apetecidos por los miembros de la más alta nobleza. Este, disponía de aposento dentro del Palacio y, junto al mayordomo mayor y el sumiller de corps, era uno de los tres grandes jefes del mismo.

En los paseos y jornadas acompañaba al coche del rey y, al contrario que en el interior de la residencia regia, tenía preeminencia sobre el resto de altos cargos ${ }^{22}$. En consecuencia, al cruzar los muros del palacio, el caballerizo mayor gozaba de un mayor acceso al monarca, siendo estos momentos los más propicios para acercarse al soberano y conseguir favores o mercedes.

Dentro de la Real Caballeriza, la autonomía de la institución a la que hacíamos referencia se veía reforzada con la de su más alto dirigente. Los miembros de la misma respondían exclusivamente ante el caballerizo mayor, quien actuaba como máxima autoridad jurisdiccional. Además, era el encargado de designar a muchos de los servidores a su cargo. Únicamente debía consultar con el rey el nombramiento de los oficios más relevantes. En estos casos proponía a tres candidatos, disponiendo finalmente el monarca cuál de los tres debía jurar la plaza.

Por tanto, no es de extrañar que un oficio con tanto poder avivase el interés de las principales casas nobiliarias, que vieron en la cercanía al soberano una forma de alcanzar sus aspiraciones políticas. Durante el reinado de Carlos III, con un sueldo de 44.000 reales anuales, el primer elegido por el monarca para regir la Real Caballeriza fue Luis Antonio Fernández de Córdoba y Spínola (1704-1768), XI

${ }^{21}$ Galán Domingo, "De las Reales Caballerizas", 223.

22 Ángel Salvador Velasco, "Las Reales Caballerizas", en Información Veterinaria, 6, (2006), 28. 
duque de Medinaceli. A su favor debió contar el hecho de haber ocupado este cargo desde el 13 de marzo de 1749 . Vivió las reformas de 1749 y 1761 y, tras la primera, pasó a ser también ballestero mayor ${ }^{23}$. Previamente, había servido como teniente general de los Reales Ejércitos y en 1748 le fue concedido el Toisón de Oro ${ }^{24}$. Permaneció en el cargo hasta su muerte en $1768^{25}$.

Rápidamente, fue nombrado como nuevo caballerizo mayor Pedro Alcántara de Guzmán (1724-1779), XIV duque de Medina Sidonia. Su carrera política era larga. El 21 de diciembre de 1738 Felipe V le concedía la llave de gentilhombre y un año más tarde marchó a vivir a la Corte. Con Fernando VI mantuvo dicho oficio y en 1751 le fue conferido el puesto de caballerizo mayor de la duquesa de Saboya. Lo desempeñó hasta 1753, año en que fue ascendido a caballerizo mayor de la Reina y recibió el Toisón de Oro ${ }^{26}$. El 28 de marzo de 1765 pasó a caballerizo mayor del Príncipe, conservando los honores de su anterior oficio ${ }^{27}$. Finalmente, el 20 de enero de 1768 juró como caballerizo mayor de Carlos III en manos del marqués de Montealegre, mayordomo mayor del rey ${ }^{28}$. Desempeñó el oficio hasta su muerte en enero de 1779.

Hasta el 24 de abril de 1780 el rey no nombró a un nuevo caballerizo mayor, quedando durante este periodo el primer caballerizo, Pedro Fitz-James Stuart, IV marqués de San Leonardo, al frente de la institución. Finalmente, el elegido fue Felipe López Pacheco y de la Cueva (1727-1798), XII marqués de Villena, quien además fue nombrado montero mayor. Previamente había sido cadete de guardia de infantería española, confiriéndosele en 1747 el regimiento de infantería de la reina. Fue miembro de la Real Academia Española, caballero de la Orden del Toisón de Oro y Comendador de la Orden de Santiago. Permaneció en el cargo hasta la muerte de Carlos III' ${ }^{29}$.

Desde el punto de vista prosopográfico, los tres casos que hemos analizado nos arrojan una imagen bastante uniforme de los perfiles que se solían tener en cuenta de cara a elegir al caballerizo mayor. En primer lugar, dos de ellos habían tenido una prestigiosa carrera militar previa, tenían una vinculación directa con las

${ }^{23}$ Luzzi Traficante, "Domesticidad, oficios y fidelidad”, 168-169.

24 AGP, Reinados, Carlos III, Caballerizas, caja 599, exp.03 s.f., memorial en que se indica la fecha en que entraron en la Real Caballeriza los diferentes servidores.

25 AGP, Reinados, Carlos III, Caballerizas, caja 568, s.f., nómina de planta del mes de enero de 1768. Consultada también la web de la Fundación Casa Ducal de Medinaceli [10 de junio de 2018] http://www.fundacionmedinaceli.org/casaducal/fichaindividuo.aspx?id=200

26 Web de la Fundación Medina Sidonia [consultada el 10 de junio de 2018]: https://www.fcmedinasidonia.com/isabel_alvarez_toledo/fcmedinasidonia/4archivo/9archivo5b/5b archivo.htm

27 AGP, Reinados, Carlos III, Caballerizas, leg. 310, s.f., Real Orden del 28 de marzo de 1765.

28 AGP, Reinados, Carlos III, Caballerizas, caja 568, novedades de la mesada de enero de 1768.

${ }^{29}$ AGP, Reinados, Carlos III, Caballerizas, leg. 310, s.f., nombramiento del marqués de Villena como caballerizo mayor el 24 de abril de 1780. 
órdenes de caballería castellanas, puesto que todos fueron condecorados con el Toisón de Oro y, así mismo, todos pertenecían a grandes linajes hispanos. No obstante, como bien ha expresado Miguel Gacho Santamaría, queda atestiguado que este cargo jamás estuvo enlazado con una casa, sino que su concesión varió conforme a las circunstancias políticas del momento ${ }^{30}$.

\subsubsection{Primer caballerizo del rey}

Era el principal apoyo del caballerizo mayor en las tareas de gobierno, por lo que era fundamental que fuese un personaje cercano a él ${ }^{31}$. Su labor era fundamental en caso de ausencia de su superior, puesto que asumía todas sus funciones. Así ocurrió tras la muerte del duque de Medina Sidonia en enero de 1779. El marqués de San Leonardo, que por aquel desempeñaba el cargo, hubo de asumir la dirección de la Real Caballeriza - jurisdicción delegada - hasta el nombramiento del marqués de Villena a mediados de 1780 .

Pedro Fitz-James Stuart y Colón de Portugal (1720-1720), IV marqués de San Leonardo fue primer caballerizo del rey desde el 15 de diciembre de 1759 hasta la muerte del Carlos III $^{32}$. Segundo hijo del tercer duque de Berwick y de Liria, tras iniciarse en la caballería, pasó a la marina en 1736, llegando a ser capitán de navío en 1745. Ascendió a teniente general en 1757 y dos años más tarde vino de Nápoles como tercer jefe de la escuadra del marqués de la Victoria, que condujo al monarca y a su familia a España. Este fue uno de los principales méritos tenidos en cuenta de cara a su nombramiento como primer caballerizo ${ }^{33}$. Ascendió a capitán general de la Real Armada en $1789^{34}$.

De nuevo, nos encontramos con un perfil claramente orientado a la carrera militar y procedente de una importante casa nobiliaria que, tras la incorporación del ducado de Alba a comienzos del siglo XIX, adquiriría mucha más preponderancia.

${ }^{30}$ Miguel Gacho Santamaría, "Las Reales Caballerizas. Una institución al servicio de la corona, a través de la historia", en Historia del Carruaje en España, coord. Eduardo Galán Domingo (Madrid: Fomento de Construcciones y Contratas, 2005), 276.

31 Alejandro López Álvarez, "La caballeriza", en La Corte de Felipe IV (1621-1665). Reconfiguración de la Monarquía católica, dirs. José Martínez Millán y José Eloy Hortal Muñoz, Tomo I, vol. 2 (Madrid: Polifemo, 2015), 796-801.

32 AGP, Reinados, Carlos III, Caballerizas, caja 599, exp.03, s.f., memorial en que se indica la fecha en que entraron en la Real Caballeriza los diferentes servidores.

33 AGP, Reinados, Carlos III, Caballerizas, caja 21, exp. 213(3), s.f., órdenes del caballerizo mayor comunicadas a la veeduría general correspondientes a los seis primeros meses del reinado de Carlos III.

34 AGP, Reinados, Carlos III, Caballerizas, leg.310, s.f., real orden liberando del pago de la media anta a Pedro Stuart del 27 de marzo de 1760. 


\subsubsection{Caballerizos mayores y primeros caballerizos de los príncipes}

La desaparición de las restantes ramas de la institución entre 1749 y 1761 no conllevó la extinción de los cargos más relevantes de las caballerizas de la reina y los príncipes. Cierto es que tras la muerte de María Amalia de Sajonia no fue necesario seguir contando con un caballerizo mayor y primer caballerizo de la reina. Estas figuras reaparecerían en las nóminas de planta tras el ascenso al trono de Carlos IV.

Así mismo, es conveniente señalar que no fue hasta 1765 cuando fueron nuevamente precisos estos altos cargo al servicio del príncipe y la princesa [Tabla 1]. En agosto de ese año, el príncipe Carlos contrajo matrimonio con María Luisa de Parma, por lo que se requerían una serie de servidores que, siempre integrados dentro de la Casa del rey, asistieran a los futuros monarcas.

\begin{tabular}{|c|c|c|}
\hline \multicolumn{3}{|c|}{$\begin{array}{l}\text { [Tabla 1]: CABALLERIZOS MAYORES Y PRIMEROS CABALLERIZOS DEL } \\
\text { PRÍNCIPE Y LA PRINCESA }(1765-1788){ }^{35}\end{array}$} \\
\hline \multicolumn{3}{|c|}{ Caballerizo mayor del príncipe } \\
\hline Individuo & Reales anuales & Periodo \\
\hline Duque de Medina Sidonia & 33.000 & $1765-1768$ \\
\hline Marqués de Andía & 33.000 & $1768-1775$ \\
\hline Conde de Altamira & 33.000 & $1775-1776$ \\
\hline Marqués de Guevara & Sin sueldo & $1776-1778$ \\
\hline Marqués de Valdecarzana & 44.000 & $1778-1783$ \\
\hline Marqués de Astorga & 44.000 & $1783-1788$ \\
\hline \multicolumn{3}{|c|}{ Caballerizo mayor de la princesa } \\
\hline Conde de Altamira & 24.750 & $1765-1775$ \\
\hline Marqués de Andia & 24.750 & $1775-1788$ \\
\hline \multicolumn{3}{|c|}{ Primer caballerizo del príncipe } \\
\hline Marqués Dusmet & Sin sueldo & $1765-1767$ \\
\hline Ángel Spinola y de la Cueva & Sin sueldo & $1767-1784$ \\
\hline Conde de Lalaing & Sin sueldo & $1784-1788$ \\
\hline \multicolumn{3}{|c|}{ Primer caballerizo de la princesa } \\
\hline Marqués de Andia & 11.750 & $1765-1774$ \\
\hline Conde de Valparaíso & 11.250 & $1774-1788$ \\
\hline
\end{tabular}

De nuevo nos encontramos ante miembros de la alta nobleza, con una carrera militar previa y que habían desempeñado o desempeñarían importantes oficios dentro de la Casa Real. Además, era común que el cargo de primer caballerizo sirviese como trampolín al de caballerizo mayor. Por ejemplo, podemos citar el caso del duque de Medina Sidonia, caballerizo mayor del príncipe, quien en 1768 fue incluso ascendido a caballerizo mayor del monarca ${ }^{36}$.

35 AGP, Reinados, Carlos III, Caballerizas, cajas 565-588, nóminas de planta desde enero de 1765 a diciembre de 1788

36 AGP, Reinados, Carlos III, Caballerizas, caja 568, novedades de la mesada de enero de 1768. 


\subsubsection{Caballerizos de campo}

En la planta de 1761 se estipuló que el número de caballerizos de campo con una remuneración de 12.000 reales anuales - no debía exceder de dieciséis ${ }^{37}$. Como bien ha señalado Alejandro López Álvarez, «más que en ningún otro oficio se concitaban aquí los valores caballerescos y nobiliarios, puestos en valor a través del relevante cometido de acompañar al rey en su lucimiento» ${ }^{38}$. Consecuentemente, en las salidas públicas debían acompañar al coche del monarca, siempre dando precedencia al caballerizo mayor y al primer caballerizo. Así mismo, en esta nueva ordenanza, se exigía que estos empleos debían recaer en los caballeros pajes del rey o en personas de la distinción correspondiente, siendo así uno de los principales destinos a los que podían aspirar aquellos que finalizaban su instrucción en la casa de pajes $^{39}$.

No obstante, la nueva planta trajo también algunos problemas de cara a la incorporación de los caballerizos provenientes de la extinta Caballeriza de la Reina. Como ya comentábamos anteriormente, los individuos para los que no se encontró una plaza inmediata quedarían fuera de las nóminas de planta, aunque conservarían su sueldo. Aun así, estos sujetos temían que con su paso a la Caballeriza del rey no se respetase su antigüedad o tuviesen precedencia caballerizos del monarca con una trayectoria inferior a la suya. Por ello, la reforma hubo de dejar claro que los empleados llegados de la Caballeriza de la reina lo hicieran «sin distinción de clases gozando cada uno en la del rey la antigüedad de su juramento» ${ }^{40}$.

\subsubsection{Veeduría y contaduría general}

Hasta 1761 el oficio de veedor y contador fue desempeñado por un solo individuo. Sin embargo, con la nueva planta de ese año los oficios de cuenta y razón se dividieron en dos oficinas - una de veeduría y la otra de contaduría general encargadas de llevar al día los pagos y de supervisar al resto de departamentos de la institución [Tabla 2] $]^{41}$.

\footnotetext{
${ }^{37}$ AGP, Reinados, Carlos III, Caballerizas, leg. 310, s.f., expediente del caballerizo de campo Cipriano Miguel de Anduaga.

${ }^{38}$ López Álvarez, "La caballeriza”, 948.

39 AGP, Reinados, Carlos III, Caballerizas, caja 599, exp. 03, artículos diversos de las ordenanzas de 1761 para la Caballeriza del rey.

40 AGP, Reinados, Carlos III, Caballerizas, leg. 310, s.f., carta del duque de Medinaceli del 11 de marzo de 1761.

${ }^{41}$ Gacho Santamaría, “Las Reales Caballerizas. Una institución”, 276.
} 


\begin{tabular}{|l|c|c|}
\hline \multicolumn{2}{|c|}{$\begin{array}{c}\text { [Tabla 2]: ESTRUCTURA DE LAS OFICINAS DE VEEDURIA Y } \\
\text { CONTADURÍA GENERAL TRAS LA REFORMA DE 176142 }\end{array}$} \\
\hline \multicolumn{2}{|c|}{ Individuo } & Cargo \\
\hline \multicolumn{2}{|c|}{ Veeduría general } \\
\hline Juan Francisco de Garaicoechea & Veedor general & 36.000 \\
\hline Juan Ramón de Mena & Oficial mayor & 10.500 \\
\hline Román de Villanueva & Oficial segundo & 8.500 \\
\hline Francisco Miguel Suarez & Oficial Tercero & 6.500 \\
\hline Fortunato Contardi & Oficial escribiente & 4.400 \\
\hline Joseph Trapani & Oficial escribiente & 3.300 \\
\hline Joseph Prieto & Portero & 3.300 \\
\hline \multicolumn{2}{|c|}{ Contaduría general } \\
\hline Manuel Petriz y Manrique & Contador General & 24.000 \\
\hline Diego Vázquez & Oficial mayor & 10.000 \\
\hline Carlos Manuel González & Oficial segundo & 8.000 \\
\hline Cayetano Urbaneja & Oficial tercero & 6.000 \\
\hline Cayetano Narciso García & Oficial cuarto & 4.500 \\
\hline Miguel Ruiz Díaz & Oficial escribiente & 4.000 \\
\hline Juan Antonio Brun y López & Oficial Escribiente & 3.300 \\
\hline Diego Fernández & Portero & 2.200 \\
\hline
\end{tabular}

Ante estos cambios, la instrucción elaborada para la Real Caballeriza debía dejar claro cuales iban a ser las competencias que debía asumir cada una de estas oficinas. Por ello, en el punto IV de la misma se estipulaba que:

El ejercicio y servidumbre del veedor general ha de continuar bajo las órdenes de mi caballerizo y ballestero mayor, el cual le comunicará mis reales órdenes y las suyas para cuanto ocurra de mi real servidumbre, las cuales después de haber dispuesto la parte que le toca a su cumplimiento las pasará a la oficina del contador para que se archiven y sirvan de justificación a lo que se manda ${ }^{43}$.

Asimismo, en cuanto a la elección de los cargos vinculados a estas dependencias de la Real Caballeriza, en los puntos V y VI de la ordenanza se fijaba el procedimiento a seguir. Los cargos de veedor y contador, al ser ocupaciones relevantes, debían ser consultadas al rey por el caballerizo mayor, siendo seleccionado

42 AGP, Reinados, Carlos III, Caballerizas, caja 560, reglamento expedido y mandado observar por su majestad a partir del 11 de septiembre de 1761.

43 AGP, Reinados, Carlos III, Caballerizas, caja 599, exp. 03, punto IV de la nueva planta de 1761 para la Real Caballeriza. 
finalmente aquel individuo que gozaba del real agrado. Lo mismo ocurría en lo tocante al nombramiento de los oficiales, que también eran cargos de importancia ${ }^{44}$.

\subsubsection{Juzgado}

Con la nueva planta, el juzgado de la Real Caballeriza se mantuvo sin grandes alteraciones. La única modificación reseñable fue la aparición de un nuevo alguacil [Tabla 3]. En lo restante, mantuvo su funcionamiento tradicional con el asesor al frente que, en la práctica, desempeñaba labores análogas a las de un juez.

\begin{tabular}{|l|l|c|}
\hline \multicolumn{1}{|c|}{ [Tabla 3]: JUZGADO DE LA CABALLERIZA TRAS LA REFORMA DE $\mathbf{1 7 6 1}^{\mathbf{4 5}}$} \\
\hline \multicolumn{1}{|c|}{ Personaje } & \multicolumn{1}{|c|}{ Cargo } & Salario anual \\
\hline Pedro Colon de Larreategui & Asesor & 2.200 \\
\hline $\begin{array}{l}\text { Francisco Fernández de } \\
\text { Mendíbil }\end{array}$ & Abogado fiscal & 750 \\
\hline Diego Sastre Navas & Secretario & 1.100 \\
\hline Juan Baptista de Aranda & Alguacil de dicho juzgado & 5 reales diarios \\
\hline Mateo Antonio Díaz & Alguacil de dicho juzgado & 5 reales diarios \\
\hline
\end{tabular}

\subsubsection{Secretario de la Real Caballeriza}

El secretario era tal vez el personaje más cercano al caballerizo mayor. Era nombrado por este dirigente y tenía la misma consideración social que los gentileshombres de boca o casa, por lo que fue un cargo que ocasionalmente despertó el interés nobiliario ${ }^{46}$. Con la llegada de cada nuevo caballerizo mayor, era habitual que este seleccionara a un nuevo secretario personal, por lo que para todo importaba que esta plaza fuese ocupada por alguien de su confianza [Tabla 4].

\begin{tabular}{|l|c|c|c|}
\hline \multicolumn{4}{|c|}{ [Tabla 4]: SECRETARIOS DE LA REAL CABALLERIZA (1759-1788) } \\
\hline \multicolumn{1}{|c|}{ Secretario } & Periodo & Caballerizo mayor & Reales anuales \\
\hline Juan Baptista de Aguirre & $1759-1768$ & Duque de Medinaceli & 6.600 \\
\hline Bartolomé José Moreno & $1768-1769$ & & 6.600 \\
\hline Gabriel Ortiz de Cagiguera & $1769-1779$ & Duque de Medina Sidonia & 6.600 \\
\end{tabular}

${ }^{44}$ AGP, Reinados, Carlos III, Caballerizas, caja 599, exp. 03, puntos V y VI de la nueva planta de 1761 para la Real Caballeriza.

45 AGP, Reinados, Carlos III, Caballerizas, caja 560, reglamento expedido y mandado observar por S.M. el 11 de septiembre de 1761.

${ }^{46}$ Gacho Santamaría, "Las Reales Caballerizas. Una institución”, 276.

${ }^{47}$ AGP, Reinados, Carlos III, Caballerizas, caja 599, exp.03 s.f., memorial en que se indica la fecha en que entraron en la Real Caballeriza los diferentes servidores; caja 568, s.f., nómina de planta del mes de enero de 1768; caja 569, s.f., novedades de la mesada de septiembre de 1769; caja 579, s.f., nómina de planta del mes de enero de 1779; caja 580, s.f., novedades de la mesada de abril de 1780 ; caja 582, s.f., novedades de la mesada de febrero de 1782; leg. 310, s.f., nombramiento de Rafael Pablo de Ariza como secretario de la Real Caballeriza el 19 de febrero de 1782. 


\begin{tabular}{|l|c|c|c|}
\hline Joaquín de Cabrera & $1780-1782$ & \multirow{2}{*}{ Marqués de Villena } & 6.600 \\
\hline Rafael Pablo de Ariza & $1782-1788$ & & 6.600 \\
\hline
\end{tabular}

\subsection{Oficios vinculados con el ceremonial cortesano}

Hemos comentado anteriormente la importancia de la Real Caballeriza dentro del conjunto de ceremonias y actos de la vida regia que se celebraban extramuros de los Reales Sitios. Sin embargo, todavía nos queda referirnos al gran abanico de oficios existentes para asegurar que la familia real se mostrase con toda la magnificencia necesaria. Empleos a los que, en la mayoría de los casos, solo era posible llegar a través de la promoción interna. El caballerizo mayor era el encargado de otorgar estos cargos, salvo en el caso de los jefes de oficio, para cuyo nombramiento se requería resolución previa del rey ${ }^{48}$.

\subsubsection{Real Armería}

Con el cambio de dinastía y la implementación de las modas francesas hubo un cambio en el gusto de la Corte. A ello, cabe sumar la progresiva desaparición de las armaduras, por lo que la colección del rey pasó a estar formada en gran medida por armas de fuego, obtenidas como trofeos militares o regalos diplomáticos ${ }^{49}$.

En cuanto a los oficios que encontramos dentro de la Real Armería, que hemos incluido en este apartado debido a su vinculación con la apariencia externa del monarca, podemos destacar en primer lugar al armero mayor. Durante el reinado de Carlos III, únicamente desempeñó este oficio Francisco Antonio de Acosta, quien percibía 6.000 reales anuales por su oficio. Junto a él, encontramos únicamente a dos armeros a 2.000 reales cada uno al año ${ }^{50}$.

\subsubsection{Reyes de armas}

Con la nueva dinastía, el cargo de rey de armas también perdió presencia dentro de las funciones palatinas. Principalmente, participaban en los actos vinculados a la jura de reyes y príncipes y en la firma de tratados de paz. Entre sus atribuciones, cabe destacar además el poder de otorgar las certificaciones relativas a

48 Así se estipuló en el punto XIII de la nueva ordenanza. AGP, Reinados, Carlos III, Caballerizas, caja 599, exp. 03, s.f., composición de la Real Caballeriza con la reforma de 1761.

49 Álvaro Soler del Campo, "La Real Armería de Madrid”, Arbor, CLXIX, 665 (mayo 2001), 156157.

50 AGP, Reinados, Carlos III, Caballerizas, leg. 312, Nota de los sueldos que gozan al año y les corresponde percibir mensualmente, según sus clases, los excelentísimos señores caballerizos mayores, primeros y demás dependientes de planta y plana mayor de la Real Caballeriza y Ballestería según la última planta de 11 de septiembre de 1761 y posteriores reales órdenes que ha habido para ello. 
los escudos de $\operatorname{armas}^{51}$. A nivel salarial, los cuatro individuos que asistían al rey en este empleo percibían 2.400 reales anuales por su servicio ${ }^{52}$.

\subsubsection{Maceros}

Este cargo de ascendencia medieval tenía como principal atribución ejercer como escolta de la comitiva real durante la jura de reyes y príncipes. Por ello, en la práctica eran los encargados de velar por la seguridad del monarca incluso tras su muerte, por lo que tras su fallecimiento se posicionaban junto a su féretro ${ }^{53}$.

\subsubsection{Real Casa de Caballeros Pajes}

Esta institución, anexa a la Real Caballeriza, tenía como objetivo fundamental formar a los caballeros pajes que debían servir al rey, precisándose así un número importante de profesores en materias típicamente cortesanas como matemáticas, latinidad, retórica, primeras letras, gramática castellana o lengua francesa. La Casa de Pajes quedaba así bajo la supervisión del caballerizo mayor, quien era el encargado de proponer al rey los candidatos que habían de optar a una de sus plazas ${ }^{54}$.

El origen de estos caballeros pajes - cuya edad estaba comprendida entre los 8 y los 14 años - es un aspecto que inequívocamente debemos analizar desde un enfoque prosopográfico. Al hacerlo, descubrimos que muchos de estos niños eran hijos de nobles o importantes servidores dentro de la Casa Real. Posteriormente, una vez finalizada su formación, los pajes eran promocionados a importantes puestos, siendo los más comunes el de caballerizo de campo y el de teniente o capitán de un regimiento. De ahí, eran promovidos a otros mucho más relevantes, tanto dentro como fuera de la Casa Real. Por ello, la importancia de esta institución radicaba en que era el lugar donde se formaba la nobleza que posteriormente iba a desempeñar los principales cargos de gobierno. De esta forma, la Casa de Caballeros Pajes fue el principal enclave «donde se aprecia que la caballeriza era un semillero de nobleza y un elemento esencial en la integración de las elites cortesanas» ${ }^{55}$.

Tras la reforma de 1749, el número de pajes se redujo de veinticuatro a doce ${ }^{56}$. No obstante, el 29 de diciembre de 1759, Carlos III ordenaría al caballerizo mayor, duque de Medinaceli, la labor de reformar la Casa de Pajes. El monarca exponía que

\footnotetext{
${ }^{51}$ Gacho Santamaría, "Las Reales Caballerizas. Una institución”, 278.

52 AGP, Reinados, Carlos III, Caballerizas, caja 560, reglamento expedido y mandado observar por su majestad a partir del 11 de septiembre de 1761.

${ }^{53}$ Gacho Santamaría, "Las Reales Caballerizas. Una institución”, 278.

54 Arantxa Domingo Malvadi, La Real Casa de Caballeros Pajes. Su historia y su proyecto educativo en la España de la Ilustración (Valladolid: Universidad de Valladolid, 2012), 22-32.

55 López Álvarez, "La caballeriza", 967.

56 AGP, Reinados, Carlos III, Caballerizas, leg. 138, s.f., reglamento de los individuos y dependientes de que se ha de componer la Casa de Caballeros Pajes de Su Majestad y sueldos que han de gozar al año dentro del nuevo Reglamento de 1749.
} 
los principios fundamentales en los que debía basarse la nueva ordenanza debían ser: aumentar nuevamente de doce a veinticuatro el número de pajes y observar la planta que se seguía en Nápoles ${ }^{57}$.

La exigencia de basarse en la Casa de Pajes de Nápoles era toda una declaración de intenciones, puesto que el nuevo rey llegaba aparentemente decidido a regirse conforme a las pautas que había seguido en aquella Corte.

Unos meses más tarde, el 31 de mayo de 1760, el caballerizo mayor presentaría su propuesta. En ella se estipulaba el número de sirvientes, clases y sueldo siguiendo, como mencionábamos, la planta napolitana [Tabla 5].

\begin{tabular}{|c|c|c|c|c|c|}
\hline \multicolumn{6}{|c|}{$\begin{array}{c}\text { [Tabla 5]: SERVIDORES EN LAS PLANTAS DE } 1749 \text { Y } 1760 \text { PARA LA CASA } \\
\text { DE CABALLEROS PAJES }{ }^{58}\end{array}$} \\
\hline Cargo & $\begin{array}{c}\text { Total } \\
\text { sueldos } 1749 \\
\text { (en reales de } \\
\text { vellón) }\end{array}$ & $\begin{array}{c}N^{\circ} \\
1749\end{array}$ & $\begin{array}{l}\text { Total sueldos } \\
1760 \text { (en reales } \\
\text { de vellón) }\end{array}$ & $\begin{array}{c}N^{\circ} \\
1760\end{array}$ & $\begin{array}{l}\text { Aumento al año } \\
\text { (en reales de v.) }\end{array}$ \\
\hline Ayo & 13.500 & 1 & 13.500 & 1 & $=$ \\
\hline Capellanes & 8.800 & 1 & $14.600^{59}$ & 4 & +5.800 \\
\hline Maestros & 11.300 & 5 & $9.125^{60}$ & 3 & -2.175 \\
\hline Mayordomo & - & - & 5.500 & 1 & +5.500 \\
\hline Ayudas de cámara & 7.300 & 4 & 23.360 & 8 & +16.060 \\
\hline Barrenderos & 1.460 & 1 & 4.380 & 2 & +2.920 \\
\hline Cocinero & 2.200 & 1 & 2.920 & 1 & +720 \\
\hline Ayuda de cocina & 1.100 & 1 & 1.825 & 1 & +725 \\
\hline Mozo de cocina & - & - & 1.100 & 1 & +1.100 \\
\hline Repostero & 2.200 & 1 & 2.920 & 1 & +720 \\
\hline Ayuda de repostería & 1.100 & 1 & 1.825 & 1 & +725 \\
\hline Mozo de repostería & - & - & 1.100 & 1 & +1.100 \\
\hline Lavandera & 2.300 & 1 & 4.380 & 1 & +2.080 \\
\hline Otra lavandera & - & - & 3.650 & 1 & +3.650 \\
\hline Almidonadora & - & - & 3.650 & 1 & +3.650 \\
\hline Médico & 1.625 & 1 & 2.750 & 1 & +1.126 \\
\hline Cirujano & 2.200 & 1 & 2.750 & 1 & +550 \\
\hline Comprador & 2.200 & 1 & 2.190 & 1 & -10 \\
\hline Enfermero & 1.825 & 1 & - & - & -1.825 \\
\hline Barbero & 1.100 & 1 & - & - & -1.100 \\
\hline
\end{tabular}

${ }^{57}$ AGP, Reinados, Carlos III, Caballerizas, caja 603, exp. 02, s.f., carta del duque de Medinaceli del 14 de diciembre de 1760 en que informa del nombre de los nuevos doce pajes que pasan a servir al rey.

58 AGP, Reinados, Carlos III, Caballerizas, leg 316, s.f., nueva planta para la casa de Caballeros Pajes de 1760.

${ }^{59}$ Con sueldos iguales de 3650 reales de vellón, habría un capellán y maestro de primeras letras, otro capellán y maestro de gramática, otro capellán y maestro de retórica y filosofía, y un cuarto para lo propio de matemáticas además de capellán.

${ }^{60}$ Un maestro de armas (2555 reales de vellón), otro de lengua francesa (3285 reales de vellón) y otro de baile (3285 reales de vellón). 


\begin{tabular}{|l|c|c|c|c|c|}
\hline Portero & 1.650 & 1 & - & - & -1.650 \\
\hline TOTAL (r. de v.) & $\mathbf{6 1 . 8 6 0}$ & $\mathbf{2 3}$ & $\mathbf{1 0 1 . 5 2 5}$ & $\mathbf{3 1}$ & $\mathbf{+ 3 9 . 6 6 5}$ \\
\hline
\end{tabular}

Del mismo modo, Medinaceli planteaba la necesidad de alquilar una nueva casa en la que hospedar a los caballeros, puesto que aquella en la que residían, próxima al Palacio Real, debía ser demolida para continuar con las obras de la residencia regia. Concretamente, proponía para tal fin la Casa Arzobispal situada junto a San Justo, en la que solamente serían necesarias algunas reparaciones superficiales.

Finalmente, el nuevo reglamento vería la luz el 21 de diciembre de 1760. En él quedaban definidos en veintiocho puntos todos los preceptos por los que se debía regir la Casa de Pajes, desde la forma en que había de servir al rey hasta como debían obtener sus uniformes ${ }^{61}$.

Sin embargo, durante los últimos años del reinado de Carlos III la Casa de Caballeros Pajes sufrió una trasformación mucho más profunda. El 17 de julio de 1786 el soberano tomó la decisión de incorporarla al Real Seminario de Nobles ${ }^{62}$. En consecuencia, con esta resolución se unificaban los dos principales organismos encargados de la formación de las élites que posteriormente iban a desempeñar los principales cargos de gobierno.

El Real Seminario fue creado por Felipe V a imitación del parisino Louis-leGrand. Con la incorporación, se equiparaban ambas instituciones: adoptando los pajes el reglamento y normas del Seminario ${ }^{63}$. Entre estas, cabe destacar la regulación de la edad de ingreso, que a partir de entonces debía estar comprendida entre los 8 y 12 años. También se aumentó la cantidad asignada a cada paje, que pasó de 12 a 14 reales de vellón diarios ${ }^{64}$.

El traslado se realizó finalmente el 1 de octubre de 1786. No obstante, los problemas no tardaron en llegar. Junto a la imposibilidad de reducir el gasto económico, que en definitiva había motivado la unificación, los caballeros pajes nunca terminaron de adaptarse al Real Seminario, puesto que siempre se sintieron superiores al resto de jóvenes nobles que allí residían ${ }^{65}$. Por todo ello, tras la destitución de Floridablanca en 1792, Carlos IV ordenó volver a separar a los pajes

${ }^{61}$ AGP, Reinados, Carlos III, Caballerizas, leg. 599, exp.03, s.f., Reglamento, planta e instrucción que se debe observar en la casa de los caballeros pajes de nuestro señor, firmado por el duque de Medinaceli, caballerizo mayor, el 21 de diciembre de 1760.

62 AGP, Reinados, Carlos III, caja 604, exp.01, s.f., carta del conde de Floridablanca al marqués de Villena del 17 de julio de 1786.

${ }^{63}$ Domingo Malvadi, La Real Casa de Caballeros Pajes, 29, 212.

${ }^{64}$ AGP, Reinados, Carlos III, Caballerizas, caja 604, exp.01, s.f., Conjunto de reglas por las que debía regirse la incorporación de los Caballeros Pajes al Real Seminario de Nobles, con fecha del 17 de julio de 1786. En concreto, el aumento de la remuneración de los pajes y la edad que estos debían tener en el momento de su entrada se estipula en los puntos 8 y 9 de dicha normativa.

${ }^{65}$ Domingo Malvadi, La Real Casa de Caballeros Pajes, 34-35. 
del Real Seminario y reubicarlos, siendo preciso un nuevo reglamento para la renacida Casa de Caballeros Pajes ${ }^{66}$.

\subsection{El cuidado de animales: los cuarteles}

El ámbito más especializado de la Real Caballeriza era el cuidado de los animales de la institución. Encontraremos aquí una serie de oficios altamente técnicos, pero no por ello menos importantes, ya que como bien ha señalado Marcelo Luzzi:

El caballo como reflejo y metáfora de la Monarquía construía y presentaba un discurso de soberanía y de identidad de majestad vinculado a la destreza física, doma y control que el monarca ejercía sobre el mismo caballo. La cultura ecuestre y el ideal del caballero fueron igualmente, desde la obra de Castiglione, elementos articuladores de la presentación de soberanía y de la majestad $^{67}$.

\subsubsection{Cuartel de regalada y picadero}

El Cuartel de Regalada tenía como principal labor la distribución diaria de caballos para el servicio regio. Al frente del mismo se encontraba el palafrenero mayor, quien a su vez era el jefe de los picadores y ostentaba el privilegio de llevar el cordón del palafrén del rey en los actos públicos ${ }^{68}$. Durante el reinado de Carlos III Bartolomé Bujones, barón de San Martín, fue palafrenero mayor desde 1759 hasta su muerte el 30 de septiembre $1780^{69}$. En ese momento fue elegido para dirigir el cuartel Antonio Valdecantos, quien desempeñó este oficio hasta el fallecimiento del monarca $^{70}$.

El palafrenero mayor contaba así mismo con la ayuda de un teniente de palafrenero quien, en caso de ausencia del primero, dirigía el cuartel. Entre los individuos que desempeñaron este oficio citaremos en primer lugar a Fernando de Moya (1759-1762), quien a su muerte sería sucedido por Pedro Melendro (1762$1769)^{71}$. El siguiente en desempeñar el oficio tras el paso de Melendro a jefe de guadarnés fue Antonio Valdecantos (1769-1780), quien tras su ascenso a palafrenero

\footnotetext{
${ }^{66}$ Real Biblioteca, IV/5602, Reglamento para la Real Casa de Pajes de Su Majestad con las instrucciones y advertencias para sus ayos y maestros, Madrid, Imprenta Real, 1792.

${ }^{67}$ Luzzi Traficante, "Domesticidad, oficios y fidelidad", 157.

${ }^{68}$ Gacho Santamaría, "Las Reales Caballerizas. Una institución”, 276.

${ }^{69}$ AGP, Reinados, Carlos III, Caballerizas, caja 580, s.f., novedades de la mesada de septiembre de 1780.

${ }^{70}$ AGP, Reinados, Carlos III, Caballerizas, leg. 310, s.f., carta del marqués de Villena del 8 de octubre de 1780 .

71 AGP, Reinados, Carlos III, Caballerizas, caja 24, exp.01, s.f., nombramiento de Pedro Melendro como teniente de palafrenero el 26 noviembre 1762.
} 
mayor sería sustituido por José del Valle $(1780-1788)^{72}$. Todos estos individuos habían servido previamente como picadores o habían tenido una carrera militar previa de prestigio que justificó su nombramiento para un puesto tan relevante.

Por su parte, tres picadores eran los encargados de enseñar a montar a caballo a los miembros de la familia real. Con la reforma de 1761 se estipuló así mismo que estos individuos debían llevar el caballo del rey en el campo, labor que hasta entonces había desempeñado el caballerizo mayor, quien seguiría haciéndolo en las ceremonias en la Corte $^{73}$. Estos, contaban así mismo con la colaboración de ayudantes, domadores y un herrador de caminos cuyas principales tareas eran herrar a los caballos y acompañar al soberano en sus salidas.

También dependían de la Real Caballeriza de Regalada los trompetas y timbaleros, cuya labor era acompañar al rey en actos públicos, siendo especialmente relevantes en las ceremonias al aire libre y durante las entradas en villas y juramentos de reyes y príncipes ${ }^{74}$.

\begin{tabular}{|l|c|}
\hline \multicolumn{1}{|c|}{ [Tabla 6]: PLANTA DEL CUARTEL DE REGALADA EN 176175 } \\
\hline \multicolumn{1}{|c|}{ Cargo } & Salario anual \\
\hline Palafrenero mayor & 7.700 \\
\hline Teniente de palafrenero mayor & 4.400 \\
\hline 3 picadores ${ }^{76}$ & $12.000 / 6.000$ \\
\hline 3 Ayudas de picador & 3.000 \\
\hline 2 domadores con honores de ayuda de picador & 3.000 \\
\hline 9 domadores a 2190 reales al año & 2.190 \\
\hline 6 ayudantes a 8 reales diarios & 8 reales diarios \\
\hline 1 herrador de caminos & 1.500 \\
\hline 1 herrador y albéitar & 31 reales diarios \\
\hline 4 trompetistas & 3.650 \\
\hline 1 timbalero & 3.285 \\
\hline
\end{tabular}

\subsubsection{Cuartel del sobrestante}

El sobrestante o cochero mayor era el encargado de cuidar los coches, berlinas, estufas y literas utilizadas por la familia real en sus apariciones púbicas. Este era asistido por ocho correos quienes, además de la entrega de cartas, tenían una misión fundamental durante las salidas públicas. En las jornadas, eran los encargados

\footnotetext{
72 AGP, Reinados, Carlos III, Caballerizas, caja 580, s.f., novedades de la mesada de noviembre de

73 AGP, Reinados, Carlos III, Caballerizas, caja 599, exp. 03, Artículos diversos de las ordenanzas de 1761 para la Caballeriza del rey.

${ }^{74}$ Gacho Santamaría, "Las Reales Caballerizas. Una institución”, 276.

75 AGP, Reinados, Carlos III, Caballerizas, caja 560, reglamento expedido y mandado observar por su majestad a partir del 11 de septiembre de 1761.

${ }^{76}$ Uno de ellos, Nicolás María Parlapiano, percibía 12.000 al año y los otros dos 6.000 reales.
} 1780. 
de portar el cofre con la ropa del rey y, así mismo, uno de ellos debía adelantarse y preparar las paradas y cambios de posta ${ }^{77}$.

El cuartel se completaba con seis ayudas y tres herradores, encargados del cuidado de los animales.

\begin{tabular}{|l|c|}
\hline \multicolumn{2}{|c|}{ [Tabla 7]: OFICIO DE SOBRESTANTE } \\
\hline \multicolumn{1}{|c|}{ Cargo } & Sueldo anual \\
\hline Sobrestante de coches & 10.000 \\
\hline Teniente de sobrestante & 7.134 \\
\hline 8 Correos & 4.400 \\
\hline 6 ayudantes & 8 reales diarios \\
\hline 3 herradores & 1.500 \\
\hline
\end{tabular}

\subsubsection{Guadarnés}

El jefe de guadarnés tenía como principal cometido preservar las sillas de mano y las de montar. Otras de sus atribuciones era la custodia de las guarniciones de uso diario de las mulas y otros instrumentos como látigos, bridas, etc. ${ }^{79}$.

Dentro de este departamento, el jefe de oficio percibía 7.700 reales por su servicio. Para llevar a cabo sus funciones contaba con dos ayudas a 4.400 reales al año cada uno y con un mozo cuyo salario ascendía a otros $2.200^{80}$. Durante el reinado de Carlos III hubo tres jefes de guadarnés: Manuel Preciado (1759-1769), Pedro Melendro (1769-1777) y Ramón de Flores (1777-1788) ${ }^{81}$.

\subsubsection{Empleos menores: gente de librea}

Estos cuarteles se completaban con una serie de lacayos, palafreneros o cocheros que contribuían así mismo al servicio regio y que se denominan en la documentación como gente de librea. Estos individuos disponían del pertinente uniforme y aportaban servicios ocasionales o estables. Tal era el número de los individuos que componían esta sección que se creó una nómina específica para ellos.

77 Gacho Santamaría, "Las Reales Caballerizas. Una institución”, 276-278.

78 AGP, Reinados, Carlos III, Caballerizas, caja 560, reglamento expedido y mandado observar por su majestad a partir del 11 de septiembre de 1761.

${ }^{79}$ Gacho Santamaría, "Las Reales Caballerizas. Una institución”, 278-279.

80 AGP, Reinados, Carlos III, Caballerizas, leg. 312, Nota de los sueldos que gozan al año y les corresponde percibir mensualmente, según sus clases, los excelentísimos señores caballerizos mayores, primeros y demás dependientes de planta y plana mayor de la Real Caballeriza y Ballestería según la última planta de 11 de septiembre de 1761.

81 AGP, Reinados, Carlos III, Caballerizas, caja 599, exp.03 s.f., memorial en que se indica la fecha en que entraron en la Real Caballeriza los diferentes servidores; leg. 310, s.f., carta del duque de Medina Sidonia confirmando el nombramiento de Pedro Melendro como jefe de guadarnés el 13 de septiembre de 1769 y del 14 de septiembre de 1777 confirmando a Ramón de Flores. 


\begin{tabular}{|l|c|c|c|c|c|c|c|c|c|c|c|c|c|c|}
\hline \multicolumn{10}{|c|}{ Tabla 9]: GENTE DE LIBREA ENTRE 1775 Y 17882 } \\
\hline & $\mathbf{1 7 7}$ & $\mathbf{1 7 7}$ & $\mathbf{1 7 7}$ & $\mathbf{1 7 7}$ & $\mathbf{1 7 7}$ & $\mathbf{1 7 8}$ & $\mathbf{1 7}$ & $\mathbf{1 7 8}$ & $\mathbf{1 7 8}$ & $\mathbf{1 7 8}$ & $\mathbf{1 7 8}$ & $\mathbf{1 7 8}$ & $\mathbf{1 7 8}$ & $\mathbf{1 7 8}$ \\
& $\mathbf{5}$ & $\mathbf{6}$ & $\mathbf{7}$ & $\mathbf{8}$ & $\mathbf{9}$ & $\mathbf{0}$ & $\mathbf{8 1}$ & $\mathbf{2}$ & $\mathbf{3}$ & $\mathbf{4}$ & $\mathbf{5}$ & $\mathbf{6}$ & $\mathbf{7}$ & $\mathbf{8}$ \\
\hline Palafreneros & 12 & 12 & 12 & 12 & 12 & 12 & 12 & 13 & 12 & 12 & 12 & 130 & 12 & 129 \\
& 9 & 9 & 6 & 6 & 4 & 7 & 6 & 0 & 5 & 6 & 6 & & 4 & \\
\hline Lacayos & 36 & 36 & 36 & 36 & 35 & 36 & 35 & 36 & 36 & 36 & 36 & 36 & 36 & 36 \\
\hline De trenes & - & - & - & - & 5 & 5 & 8 & 9 & 9 & 9 & 9 & 9 & 9 & 9 \\
\hline Volantes & 7 & 7 & 7 & 7 & 7 & 7 & 7 & 7 & 7 & 7 & 6 & 6 & 6 & 6 \\
\hline $\begin{array}{l}\text { Mozos de } \\
\text { silla }\end{array}$ & 10 & 12 & 12 & 12 & 12 & 12 & 12 & 12 & 12 & 12 & 12 & 12 & 18 & 17 \\
\hline $\begin{array}{l}\text { Guardacoch } \\
\text { es }\end{array}$ & 2 & 1 & 1 & 1 & 1 & 1 & 1 & 1 & 1 & 1 & 1 & 1 & 1 & 2 \\
\hline Cocheros & 91 & 87 & 10 & 10 & 10 & 10 & 10 & 10 & 10 & 10 & 10 & 107 & 11 & 109 \\
& & & 9 & 9 & 7 & 3 & 9 & 8 & 9 & 9 & 9 & & 2 & \\
\hline Mancebos & 21 & 20 & 28 & 28 & 27 & 27 & 27 & 28 & 27 & 28 & 28 & 299 & 28 & 298 \\
& 4 & 8 & 5 & 3 & 9 & 2 & 5 & 6 & 3 & 3 & 1 & 83 & 0 & 84 \\
\hline Lavacoches & - & - & - & 8 & 8 & 7 & 7 & - & 8 & 8 & 8 & - & 8 & - \\
\hline Cajoneros & 3 & 3 & 6 & 6 & 6 & 6 & 6 & 5 & 5 & 8 & 8 & - & 8 & - \\
\hline Litereros & 5 & 4 & 3 & 3 & 3 & 3 & 3 & 2 & 2 & 3 & 3 & - & 3 & - \\
\hline $\begin{array}{l}\text { Mozos } \\
\text { napolitanos }\end{array}$ & 66 & 69 & 69 & 68 & 66 & 67 & 75 & 81 & 86 & 81 & 80 & 93 & 97 & 99 \\
\hline
\end{tabular}

La continua entrada y salida de individuos en estos oficios hace que trazar sus trayectorias dentro del servicio regio sea un aspecto complicado, ya que muchos de ellos sirvieron durante periodos muy breves y luego desaparecen de las nóminas. No obstante, tratándose del cuerpo más numeroso de la Real Caballeriza, debemos tenerlos en cuenta para entender la magnitud de la institución.

\subsection{Real Ballestería}

La Real Ballestería se incorporó a la Caballeriza en el siglo XVII. Cabe reflexionar acerca del hecho que, desde la reforma de 1749, el caballerizo mayor fuese a su vez ballestero mayor. La equiparación de ambos oficios no es sino una muestra inequívoca de la importancia otorgada a esta institución encargada de gestionar las cacerías de la familia real.

A este le asistían dos ballesteros principales que durante las cacerías se encargaban de cargar las escopetas. Junto a ellos encontramos a once ballesteros ordinarios y diez agregados que marchaban a la cabeza de las batidas, siendo uno de los ordinarios el encargado de entregar las armas al rey. Los ballesteros ordinarios eran los que habían formado parte de la Caballeriza del rey hasta la reforma de 1761, mientras que los agregados eran los que procedían de la extinta Caballeriza de la

\footnotetext{
82 AGP, Reinados, Carlos III, Caballerizas, cajas 575-588, nóminas de la gente de librea entre enero de 1775 y diciembre de 1788. Previamente no encontramos relaciones completas de estos dependientes.

${ }^{83}$ Incluye mancebos, cajoneros, litereros y lavacoches.

${ }^{84}$ Ibídem.
} 
Reina $^{85}$. Junto a ellos encontramos otros cargos destinados a facilitar su labor a los ballesteros [Tabla 8].

\begin{tabular}{|l|c|}
\hline \multicolumn{2}{|c|}{ [Tabla 8]: REAL BALLESTERIA } \\
\hline 2 ballesteros principales \\
\hline 11 ballesteros ordinarios (8800 al año) & 15.000 \\
\hline 10 ballesteros agregados (4400 al año) & 8.800 \\
\hline Médico & 4.400 \\
\hline Cirujano & 6.600 \\
\hline 4 arcabuceros & 5.500 \\
\hline 16 mozos de traílla & 3.300 \\
\hline 1 halconero & 6 reales diarios \\
\hline 5 huroneros & 5 reales diarios \\
\hline 1 ayuda de huronero & 6 reales diarios \\
\hline 7 ayudas & 2.190 \\
\hline 1 pajarero & 5 reales diarios \\
\hline
\end{tabular}

\subsection{Reales Yeguadas y Praderas de Aranjuez}

Las tres Reales Yeguadas y Praderas de Aranjuez pasaron a formar parte de las Real Caballeriza el 1 de julio de $1762^{87}$. Su principal labor era abastecer de animales a la Casa Real para el servicio regio.

Desde el reinado de Carlos II las Reales Yeguadas de Aranjuez habían entrado en un proceso de declive. No sería hasta el reinado de Carlos III cuando se recuperarían, tras haber mandado el monarca construir unas nuevas infraestructuras y dividir la yeguada en tres cuarteles: uno para la cría de caballos de monta o silla de raza andaluza, otro para los caballos de tiro o cuartagos y un tercero para la cría de mulas ${ }^{88}$. No obstante, este empuje de Aranjuez trajo consigo el declive de las Caballerizas de Córdoba a partir de la década de 1780, que habían sido el centro primordial para la cría de caballos hasta la fecha ${ }^{89}$.

85 Gacho Santamaría, "Las Reales Caballerizas. Una institución”, 276.

86 AGP, Reinados, Carlos III, Caballerizas, caja 560, reglamento expedido y mandado observar por su majestad a partir del 11 de septiembre de 1761.

${ }^{87}$ AGP, Reinados, Carlos III, Caballerizas, caja 598, exp. 03, carta del duque de Medinaceli del 6 de julio de 1762. Para conocer la evolución de la yeguada en Aranjuez se puede consultar Juan Álvarez de Quindós y Baena, Descripción histórica del Real Bosque y Casa de Aranjuez, Madrid, Imprenta Real, 1804, pp. 328-330.

88 Gacho Santamaría, "Las Reales Caballerizas. Una institución”, 288.

${ }^{89} \mathrm{Al}$ respecto de la evolución de las Reales Caballerizas de Córdoba consultar Juan Aranda Doncel y José Martínez Millán, "Las Reales Caballerizas de Córdoba durante los siglos XVI y XVII: estructura administrativa e integración social" en Las Caballerizas Reales y el mundo del caballo, coord. Juan Aranda Doncel y José Martínez Millán, (Córdoba: Córdoba Ecuestre, 2016), 31-128. 


\begin{tabular}{|l|c|}
\hline \multicolumn{1}{|c|}{ CTabla 9]: REGLAMENTO PARA LAS YEGUADAS DE ARANJUEZ DE 176290 } \\
\hline \multicolumn{1}{|c|}{ Raza de Caballos } & Salario anual \\
\hline \multicolumn{1}{|c|}{ Cargo } & 4.400 \\
\hline Un Mayoral (12 reales diarios) & 2.920 \\
\hline Un soto mayoral (8 reales diarios) & 5 reales diarios \\
\hline $\begin{array}{l}\text { Doce yegüeros o pastores con 5 reales cada uno al día. Que estos variarán en el } \\
\text { más o menos según lo que sea preciso dividir el ganado con respecto a tres } \\
\text { hombres por cada uno de 40 a 50 cabezas }\end{array}$ & 4.400 \\
\hline \multicolumn{2}{|c|}{ Raza de Mulas } \\
\hline Un mayoral & 2.920 \\
\hline Un sota mayoral & 5 reales diarios \\
\hline $\begin{array}{l}\text { Doce yegüeros o pastores, que estos variarán en el más o menos según lo que } \\
\text { sea preciso dividir el ganado con respecto a 3 hombres por cada uno de 40 a 50 } \\
\text { cabezas }\end{array}$ & \\
\hline
\end{tabular}

\subsection{Dependientes de fuera de planta}

Como ya hemos venido señalando, en este grupo se incluían tanto a aquellos que habían quedado sin una plaza tras la unificación de las Casas Reales como los individuos a los que el rey les había concedido la jubilación o pensión de viudedad y seguirían gozando de una parte del que había sido su salario. Debido a la gran cantidad de individuos que componían esta sección se elaboró una nómina particular para ellos.

\section{CONCLUSIONES}

Para finalizar, me gustaría esbozar unas breves líneas acerca de todo lo que hemos señalado hasta aquí. En primer lugar, resulta evidente que tras la unión de las Casas Reales la Caballeriza, lejos de disminuir, aumentó considerablemente. Este crecimiento hizo necesaria en 1782 la construcción de un nuevo edificio capaz de albergar a todos los servidores y animales que dependían de la institución.

El arquitecto palermitano Francisco Sabatini fue el encargado de la construcción de la nueva Caballeriza. El emplazamiento que finalmente se destinó para ellas fue un gran terreno de $27.000 \mathrm{~m}^{2}$ situado en el flanco norte del Palacio, lugar hoy en día ocupado por los jardines bautizados con el nombre del propio Sabatini.

Esta construcción en sus estancias superiores podía dar cabida a hasta 500 personas. No obstante, cabe recordar que a finales del reinado de Carlos III eran cerca de un millar los dependientes que trabajaban en la Real Caballeriza. Por ello, en ningún momento pudo darse cabida al enorme contingente humano que componía la institución. Los servidores sin residencia eran distribuidos en otros edificios aledaños

${ }^{90}$ AGP, Reinados, Carlos III, Caballerizas, caja 598, exp. 03, carta del duque de Medinaceli del 8 de julio de 1762 . 
al Palacio Real o se les otorgaba una ayuda de costa para que pudiesen hacer frente a una vivienda ${ }^{91}$.

Del mismo modo, parece también contrastado que la reforma de 1761 no consiguió atajar el problema que suponía para el erario regio mantener a todos los servidores de la Caballeriza [Anexo 2]. Tal vez entramos aquí en un ámbito complejo, puesto que las intenciones de menguar el gasto topaban directamente con la imposibilidad de reducir toda la pompa que acompañaba las salidas y jornadas del monarca hispano. Dicho en otras palabras, la intención de economizar chocaba directamente con la propia constitución de la Monarquía.

Es por ello que es necesaria una lectura más profunda de los cambios experimentados en la Real Caballeriza a mediados del siglo XVIII. Tanto la reforma de 1749 como la de 1761 perseguían llevar a cabo una redefinición de la Casa Real en su conjunto. No podemos olvidar que esta era una pieza fundamental dentro de la Corte, que durante la Edad Moderna fue la propia organización política y toda actividad que no se dio dentro de la misma no existió políticamente hablando. Este modelo comenzó a cambiar durante la Ilustración y con la aparición del estado liberal, nuevo paradigma de explicación de la evolución histórica ${ }^{92}$.

Precisamente, la necesidad de reformular la Casa Real evidencia la descomposición del sistema cortesano. En consecuencia, las reformas que hemos ido analizando constituyen dos momentos clave que evidencian el agotamiento del modelo que había regido la vida política del Antiguo Régimen. Las revoluciones liberales de finales de siglo rechazarían por completo este orden basado en el clientelismo y el favor, por lo que la influencia de la Casa Real en la política tenía los días contados.

Finalmente, para cerrar este capítulo, me gustaría añadir que todos los departamentos que hemos querido reflejar en el presente artículo podrían suponer campos de estudio autónomos muy potentes. Por tanto, y especialmente desde el punto de vista prosopográfico, todavía queda mucho por hacer respecto a la Real Caballeriza y su importancia dentro de una institución fundamental como fue la Casa del rey Carlos III.

\footnotetext{
91 Ángel Salvador Velasco y Carlos Ballesteros Vicente, "La Real Caballeriza Regalada (17891934)", en Libro de Actas del XXVII Congreso Internacional de la World Association for the History of Veterinary Medicine y XII Congreso de la Asociación Española de la Veterinaria (León: 2006), 369-374.

${ }^{2}$ José Martínez Millán, "La sustitución del sistema cortesano por el paradigma del estado nacional en las investigaciones históricas", en Libros de la Corte, 1 (2010), 5-7.
} 


\section{ANEXOS DOCUMENTALES}

\section{[Anexo 1]: REGLAMENTO PARA LA REAL CABALLERIZA DE 176193}

La buena armonía y método que deseo establecer para la servidumbre de mi real caballeriza en sola una excusando por este medio superfluidades que contribuyen más que al decoro a la confusión en todas materias es perniciosa me ha parecido resolver unir la caballeriza que servía a la reina, mi muy cara y amada esposa a la mía, quedando en una sola para que indistintamente sirva y desempeñen los oficios y todas las funciones y demás servidumbres que puedan ofrecerse con la puntualidad y esplendor que conviene y en su consecuencia he mandado formar el reglamento de sueldos y ordenanza que se ha de practicar en la forma siguiente.

[Relación de todos los individuos y sueldos]

1- El caballerizo y ballestero mayor es el primer jefe de mi real caballeriza y que ha de continuar su ejercicio y servidumbre cerca de mi real persona con la inmediación que lo ejecuta en su respectiva servidumbre y como tal le corresponde privativamente el gobierno y dirección de ella con facultad de poner con su acostumbrado celo cuanto pertenezca a mi real servidumbre según conviene.

2- Mando que todos los criados e individuos de mi Real Caballeriza y agregados comprendidos en este reglamento sin excepción de persona ni clase estén a la orden de mi caballerizo mayor.

3- Para la más cuenta y razón de mi Real Caballeriza hay un contador que ha de servir como el veedor general, según la instrucción que he mandado formar en que se previene lo que a estos empleos corresponde y quiero que se observe con puntualidad y se arregle a ella en la parte que le toca mi caballerizo y ballestero mayor.

4- El ejercicio y servidumbre del veedor general ha de continuar bajo las órdenes de mi caballerizo y ballestero mayor, el cual le comunicara mis reales órdenes y las suyas para cuanto ocurra de mi real servidumbre, las cuales después de haber dispuesto la parte que le toca a su cumplimiento las pasara a la oficina del contador para que se archiven y sirvan de justificación a lo que se manda. Y el veedor general ha de poder representar a mi caballerizo y ballestero mayor todo lo que considerase correspondiente a mi servicio.

93 AGP, Reinados, Carlos III, Caballeriza, caja 599, exp.03, s.f., reglamento para la Real Caballeriza, fechado el 11 de septiembre de 1761. 
5- Los empleos de veedor general y contador se me han de consultar por el caballerizo mayor reservadamente su provisión en quien sea de mi real agrado, por la secretaria del despacho de Hacienda.

6- En las vacantes de oficiales de estas oficinas harán sus propuestas el veedor general y el contador, quien se las dirigirá al veedor para que por este se encaminen a mi secretario de Hacienda a fin de que yo resuelva lo que fuere de mi real agrado procurando distinguir siempre el mérito sin sujetarse a la antigüedad ni clase. Y como los dependientes que han servido en la liquidación de los créditos de mi caballeriza y de la de la reina están comprendidos en la planta de oficiales de la veeduría y contaduría, deberán estos u otros que se juzgaren capaces continuar bajo la dirección del contador a liquidar los referidos créditos y dar el contador las certificaciones correspondientes.

7- Queda prevenido el número de criados de planta y sueldos que han de gozar, del cual no ha de exceder sin expresa resolución mía cuando tenga por conveniente variarlo y gozar además de la regalía de médico, cirujano y botica para sus personas y una bula para cada año.

8- Los que tengan por merced o gracia particular otros goces o pensiones además del sueldo han de continuar a percibirlo sin novedad alguna como lo disfrutan actualmente.

9- En todas las vacantes que se ofrezcan para las vacantes de número de criados de mi real caballeriza me propondrá mi caballerizo mayor por sus clases y antigüedades tres sujetos de los que queden exclusos y tengan las circunstancias correspondientes para entrar en número.

10- Han de preceder los juramentos a la posesión y ejercicio de los empleos que yo conceda, y el contador tendrá la obligación de asegurar el derecho de media-annata a favor de mi real hacienda en la conformidad que está mandado y se practica actualmente.

11- Es mi voluntad que la plaza de asesor de mi real caballeriza la ocupe un ministro del Consejo de Castilla, consultándome mi caballerizo mayor tres sujetos, los que parezcan más apropósito. Que las faltas que los criados cometieren contra la servidumbre se castiguen providencialmente y gobernativamente por mi caballerizo mayor. Y si fueren tan grabes que requieran orden judicial remitirá las causas con su aviso al asesor de cuya sentencia solo se ha de apelar con permiso del mismo jefe a los asesores de la casa y cámara que convocarán donde señalare el más antiguo, para que se sentencie en revista sin apelación ni consulta. Y en esta junta hará de abogado fiscal el que lo sea de mi Real Casa. 
12- Los jefes de regalada y coche y demás de mi Real Casa han de continuar en proponer al veedor general las vacantes de mozos y demás clases de planta que no sean jurados para que haciéndolo presente a mi caballerizo mayor con su aprobación se establezca, hagan los asientos correspondientes y se les libre su haber a nombre de cada uno, que han de firmar su partida en la nómina de sueldos. Y ninguno de los expresados jefes de cuarteles ha de poder aumentar ningún mozo de los que previene el reglamento con título de jornaleros, pues en las ocasiones que sean precisos por algún motivo, darán cuenta al veedor general para que este lo haga presente a mi caballerizo mayor que lo examinará con el veedor general para que si hubiese de los exclusos de planta algunos que puedan trabajar indistintamente los destine. $\mathrm{Y}$ si fuese preciso aumentarlos lo ejecutará sin cuya circunstancia no se ha de abonar salario alguno y se ha de entender en este caso por los días que efectivamente trabajasen dándoles ración que les parezca regular sin mesilla ni otro estipendio por jornadas.

13- Es mi voluntad se continúe por la secretaria de gracia y justicia el hacerme presente las consultas de caballerizo mayor para la provisión de empleos de número que sea consultivos como son los de caballerizo de campo, asesor, armero mayor, guadarnés, los dos ayudas de este oficio, el palafrenero mayor, el teniente de los reyes de armas, los maceros, el sobrestante de coches, el teniente de picadores, ayudas, coreos, librador y ayuda de caballeros pajes, ayo, ballesteros, arcabuceros, quedando de provisión de mi caballerizo mayor los demás empleos.

14- Por la secretaria de despacho de Hacienda se me ha de hacer presente toda la consulta o representación que trate de asuntos o dominación de individuos novedades de sueldos y gratificaciones, ayudas de costa o limosnas gastos de compras, asientos de provisiones, relación de sueldos y gastos que se necesiten ordinarios y extraordinarios para mi real servidumbre y todo cuanto sea de su cargo de la real hacienda porque pertenece a mi superintendente general de ella esta inspección en virtud de las facultades de su empleo.

15- Respecto de quedar una sola familia para servir en mi real caballeriza y señalada en este reglamento la suficiente para el desempeño de cuanto ocurre, mando a mi caballerizo mayor que luego disponga se hagan inventarios de lo que resulte de cargo a cada oficio de los que comprenden mi real caballeriza con la mayor formalidad que firmaran sus respectivos jefes con intervención del contador y dichos instrumentos han de quedar en esta oficina para aumentar nuevamente todo lo que se les vaya entregando en adelante y descargando al mismo tiempo lo que se inutilizase mediante las justificaciones que deben preceder. 
16- Mando que no se pueda prestar coche alguno, mulas, caballos ni otra cosa alguna de la de los oficios de mi Real Caballeriza a cuyo cargo están los correspondientes para uso alguno que no sean de mi real servidumbre como está mandado sin permiso expreso de mi caballerizo mayor.

17- Ningún jefe de los oficios de mi Real Caballeriza podrá por si desechar ni deshacer cosa alguna perteneciente a ellos y están a su cargo sin dar parte al veedor general y este a mi caballerizo mayor, los cuales han de examinar su situación para si esta inservible sin recomposición y en este caso se dará cuenta por la secretaria del despacho de hacienda para que se ejecute el desecho o su repartimiento entre las personas que yo mandase.

18- Ningún individuo de mi real caballeriza ha de tener derecho a los sobrantes en ocasión de que el público quisiese obsequiarme el que podrá recoger los remanentes de sus efectos.

19- El carruaje, bolillos de cera y hachas de viento que se suministraran para mi Real Caballeriza por papeletas del veedor general se ha de continuar sin novedad, pero es mi voluntad que su importe se pague con los gastos de mi Real Caballeriza a fin de venir en conocimiento de lo que en cada clase se gasta y que de esta disposición se pase aviso correspondiente a mi caballerizo mayor por la secretaria de despacho de hacienda.

20- Prohíbo toda franquicia que han tenido los proveedores oficiales de manos, mercaderes y artistas respecto de pagarles con puntualidad el importe de sus géneros y trabajo de las obras.

21- Para la conducción de agua de la fuente del berro al palacio del Buen Retiro se suministrará como hasta aquí por mi Real Caballeriza u palafrén portero de la cava para que vaya a verla tomar y acompañarla desde la fuente.

22- De tres en tres años se darán a cuenta de mi Real Hacienda los pequeños uniformes a los caballerizos de campo, picadores, ayudas, correos y demás de planta mayor que sirven diariamente en el campo y la librea de campaña a los dependientes de mi Real Caballeriza.

23- Todos los individuos han de usar el uniforme así grande como pequeño y se han de ejecutar nuevos siempre que yo lo halle por conveniente a excepción de los pequeños uniformes expresados en el capítulo antecedente.

24- Es mi voluntad que en el principio de cada año o cuando se tenga por conveniente se haga en el cuarto de mi mayordomo mayor en Palacio una junta en que concurran este, mi caballerizo mayor, sumiller, patriarca, el contador y grefier de mi real casa y el veedor general y contador de mi 
caballeriza para tratar de todo lo que pueda conducir a mi mejor servidumbre y examinar los gastos que se hubieren causado el año antecedente atendiendo a los que puedan evitarse sin faltar a la decencia correspondiente. $\mathrm{Y}$ así mismo examinar las cuentas y ver si se llevan corrientes y sin atraso con las debidas formalidades prescritas en el reglamento y de resulta de esta diligencia me darán noticia puntual y un estado en que manifieste todo el gasto del año con distinción de lo consumido por cada clase. Y en esta junta hará de secretario el grefier de mi real casa capilla y cámara por lo que respecta a sus agregados y por lo de mis caballerizas el contador de ellas y de esta disposición se dará aviso a los referidos jefes principales por mi secretario de despacho de Hacienda.

25- La Casa de mis caballeros pajes continuará bajo las reglas y método con que tengo establecidos por mi real orden del 31 de diciembre de 1760 (pone 61 pero debe ser un error).

26- Mi real ballestería proseguirá como al presente en su servidumbre bajo las órdenes de mi caballerizo y ballestero mayor que es.

27- Mando que mi caballerizo mayor, veedor general contador y demás a quienes corresponde se arreglen al cumplimento de los artículos que comprenden este reglamento y ordenanza, observándolos y haciéndolos observar recíprocamente instruidos de sus facultades cada uno para que por este medio se establezca en mi real servidumbre el mejor gobierno que deseo y encargo al referido jefe emplee todo su celo a este fin en inteligencia de que quedan todos los reglamentos anteriores y que en los casos no explicados en esta ordenanza se ha de observar la costumbre como no se oponga a ella. Esta rubricado de la real mano de SM en San Idelfonso a 11 de septiembre de 1761.

\begin{tabular}{|c|c|c|c|c|}
\hline \multicolumn{5}{|c|}{$\begin{array}{l}\text { [Anexo 2]: SUELDOS, RACIONES Y GASTOS DE LAS DIFERENTES } \\
\text { SECCIONES DE LA REAL CABALLERIZA (en reales y maravedís) }\end{array}$} \\
\hline & & 1763-1779 & $1780-1785$ & 1786-1787 \\
\hline \multirow{2}{*}{$\begin{array}{l}\text { Real } \\
\text { Caballeriza: }\end{array}$} & P. & 35.911 .371 y 6 & 13.205 .150 y 4 & 4.664 .764 y 10 \\
\hline & F.P. & 8.458 .678 y 12 & 1.224 .349 y 30 & 246.185 y 14 \\
\hline \multirow{2}{*}{$\begin{array}{l}\text { Real } \\
\text { Ballestería }\end{array}$} & P. & 4.306 .046 y 1 & 1.534 .283 & 529.900 y 27 \\
\hline & F.P. & 497.555 & 510.522 y 22 & 130.179 y 17 \\
\hline Casa & P. & 3.709 .630 & 1.176 .625 y 2 & 366.776 y $21^{95}$ \\
\hline
\end{tabular}

94 AGP, Reinados, Carlos III, Caballeriza legajo 312, Representación de la junta de bureo sobre asuntos de la Real Caballeriza, 1763-1787.

${ }^{95}$ Estando la Casa de Caballeros Pajes integrada dentro del Real Seminario de Nobles desde el 1 de octubre de 1786. 


\begin{tabular}{|c|c|c|c|}
\hline Pajes & 201.572 & 45.057 y 19 & 88.579 y 16 \\
\hline Real Montería & 1.693 .041 y 12 & 552.136 & 177.194 \\
\hline Casa de Campo & 259.591 y 9 & - & - \\
\hline $\begin{array}{ll}\text { Yeguada } & \text { de } \\
\text { Aranjuez }\end{array}$ & 1.570 .712 у 3 & 379.133 & 137.417 \\
\hline $\begin{array}{l}\text { Caballeriza de la } \\
\text { reina madre }\end{array}$ & 2.228 .339 у 9 & - & 96.016 y 31 \\
\hline Vestuario & 6.440 .984 & - & - \\
\hline
\end{tabular}




\section{BIBLIOGRAFÍA}

Juan Álvarez de Quindós y Baena, Descripción histórica del Real Bosque y Casa de Aranjuez, Madrid, Imprenta Real, 1804.

Emilio de Benito, "La Real Junta de Bureo", en Cuadernos de Historia del Derecho, 1 (1994), 49-124.

Arantxa Domingo Malvadi, La Real Casa de Caballeros Pajes. Su bistoria y su proyecto educativo en la España de la Ilustración. Valladolid: Universidad de Valladolid, 2012.

Miguel Ángel Gacho Santamaría, "Las Reales Caballerizas en el Antiguo Régimen”. Tesis doctoral: Madrid, 2001.

Miguel Ángel Gacho Santamaría, "Las Reales Caballerizas. Una institución al servicio de la corona, a través de la historia", en Historia del Carruaje en España, coord. Eduardo Galán Domingo. Madrid: Fomento de Construcciones y Contratas, 2005, 274-299.

Eduardo Galán Domingo, "De las Reales Caballerizas a la Colección de Carruajes del Patrimonio Nacional”, en Arbor, XLXIX (2011), 221-238.

Carlos Gómez-Centurión Jiménez y Juan A. Sánchez Belén (eds.), La berencia de Borgoña. La hacienda de las Reales Casas durante el reinado de Felipe V. Madrid: Centro de Estudios Políticos y Constitucionales, 1998.

Carlos Gómez-Centurión Jiménez, "La reforma de las Casas Reales del marqués de la Ensenada”, en Cuadernos de Historia Moderna 20 (1998), 59-83.

José Eloy Hortal Muñoz y Félix Labrador Arroyo, La Casa de Borgoña. La Casa del rey de España. Leuven: Leuven University Press, 2014.

Alejandro López Álvarez, "La caballeriza”, en La Corte de Felipe IV (1621-1665). Reconfiguración de la Monarquía católica, dirs. José Martínez Millán y José Eloy Hortal Muñoz, Tomo I, vol. 2. Madrid: Polifemo, 2015, 795-917.

Marcelo Luzzi Traficante, "Domesticidad, oficios y fidelidad: la Caballeriza Real y la unificación de las Casas Reales en la primera mitad del siglo XVIII", en Libros de la Corte, 14 (2017), 155-171.

Rubén Mayoral López y Alejandro López Álvarez, "La caballeriza”, en La monarquía de Felipe III, coord. José Martínez Millán, vol. 1. Madrid: Fundación Mapfre, 2008, 733-810. 
Ángel Salvador Velasco y Carlos Ballesteros Vicente, "La Real Caballeriza Regalada (1789-1934)", en Libro de Actas del XXVII Congreso Internacional de la World Association for the History of Veterinary Medicine y XII Congreso de la Asociacion Española de la Veterinaria. León: 2006, 369-374.

Ángel Salvador Velasco, “Las Reales Caballerizas”, en Información Veterinaria, 6 (2006), $25-28$.

Álvaro Soler del Campo, "La Real Armería de Madrid", Arbor, CLXIX, 665 (mayo 2001), 143-162. https://doi.org/10.3989/arbor.2001.i665.876

Recibido: 31 de julio de 2018 Aprobado: 23 de octubre de 2018 